\title{
Research into Production and Management of Aviation Manufacturers Based on Lean Production
}

\author{
Wang Qingjun \\ Economics and Management Institute \\ Shenyang Aerospace University \\ Shenyang City, China \\ 32582669@qq.com
}

\author{
Wu Jingtai \\ Economics and Management Institute \\ Shenyang Aerospace University \\ Shenyang City, China
}

\begin{abstract}
In recent years, China's aviation industry has achieved obvious progress, but still lags behind that in developed countries. This paper will analyze some problems in the production and management of aviation manufacturers in China from various aspects to combine lean production with production of aviation manufacturers through introducing lean production theory and to guarantee production in enterprises through taking some safeguard measures.
\end{abstract}

Keywords-aviation manufacturing; lean production; safeguard measures

\section{INTRODUCTION}

The aviation industry, which has achieved rapid development in the new era, combines modern industry and science and technology, effectively improving people's livelihood, consolidating the national defense and improving the capacity of industrial production, thus it plays a very obvious strategic role in reflecting the comprehensive national strength, including various fields like the metallurgy, materials, electronics and controlling. As the aviation manufacturing industry plays an immeasurable role in developing national economy and coordinating the development of various categories of science, it has already become a key industry in national development. Generally, a multiple parts will be assembled correspondingly, so the aviation manufacturing industry, which belongs to the assembly manufacturing industry, is subject to the supply status of part manufacturers, and sometimes it takes one year or more on only one part, from the procurement to manufacturing. At present, China still lags behind some developed countries in the aviation manufacturing industry, which is especially obvious in management and technical aspects. This paper will analyze problems in aviation manufacturing enterprises accordingly from the perspective of management to optimize corporate management through lean production theory.

\section{OVERVIEW OF LEAN PRODUCTION THEORY}

A. Origin

When it comes to the origin of the lean production method, the Toyota production system of the Toyota Motor Corporation must be mentioned because it is a brand new production mode. After the World War II, mass production of the U.S. Ford still dominated and the motor industry in Japan was still in its infancy. The mass production was the most advanced way of management at that time with strong competitive edge because it reduced costs with less variety and large quantity. However, Toyota investigated Ford at that time, carefully summarized its both advantages and disadvantages, and the gradually perfected its own Toyota production system through constant exploration and endeavor in nearly 30 years afterwards, making the auto industry in Japan exceed that of the U.S.

The term lean production was proposed by scholars of the U.S. MIT after summarizing the punctual production theory of Toyota. "Lean" means production elements should be invested appropriately to meet the necessary amount of the market and all the operation activities are effective and beneficial. Therefore, This mode of production can be understood as being based on constantly improving concepts with the purpose of reducing costs and improving efficiency supported by being punctual and automotive [1].

\section{B. Definition and Features}

We have mentioned above that lean production was originated by the Japanese, who have been using this method for practice for fifty years. However, it has just been several years since this method was researched at the theoretical level. The term lean production was indeed proposed by scholars at the U.S. MIT, but they have not given an accurate definition of it. Professors from Beihang University clearly define lean production: It is through the personnel organization, system structure, operation mode and market supply and demand and other aspects of the reform, so that the production system to adapt to the 
requirements of the vast number of users, and to streamline all the useless and redundant in production, and finally to reach the production, including market supply, including the best results.

After concluding and summarizing features of lean production enterprises, six major features of lean production can be concluded as follows:

First, Customer is the "God". Any innovation and improvement of enterprises is nothing but to provide more affordable products for customers to meet their needs.

Second, Any production activity should be "people-centered". People are the main body of enterprises' production activities, so full play must be given to people's power through the work of team to let frontline workers truly become the main force of production and give full play to their creativity and enthusiasm so as to better guarantee the quality of products.

Third, Using this effective means of good "streamlining". Streamlining should be fully reflected in all aspects, including the organization structure to remove some unnecessary links and personnel; production process of flexible processing equipment, to reduce the number of non direct production staff, improve staff for product value; in the logistics management of JIT and Kanban method, greatly reduce inventory, so as to reduce the inventory management, equipment and place of spending. In addition, at the same time with streamlining, emphasis should also be put on providing diversified products [1].

Fourth, JIT supply method. This supply way can guarantee the minimum inventory and products. In order to make good use of this supply method, good cooperation must be kept with the suppliers with mutual help and trust.

Five, "Zero defect" at work. This is also the final goal of lean production, that is, to product the best products at the lowest cost while meeting the requirement of no waste, zero inventory and diversified products. This is an ideal status for enterprises, and also the goal that enterprises should constantly pursue. Only when there is constant pursuit, can an enterprise make constantly progress with strong competitive edge in order to be invincible [1,2].

\section{Problems in Production And Management of}

\section{AVIATION MANUFACTURERS}

The planned economic system has always been having a far-reaching impact on China's aviation manufacturing enterprises, resulting in that until now, the production modes of most aviation manufacturing enterprises are still traditional multi species and small batch production mode with relatively extensive management, so a lot of problems have also been caused in production and management.

\section{A. Functional Organization Structure and Low Efficiency in Communication}

In terms of the current organizational structure of China's aviation manufacturing enterprises, the organizational structure of the functions they use formula, since many aviation parts, so the corresponding functions very much. At the same time, as long as the product changes, it will lead to a corresponding increase in departmental staff and hierarchy. In general, an aviation enterprise has dozens of departments is more common, although this situation meticulous division of labor, but led to communication barriers. Specifically, from the lateral view, relates to a device and process coordination across sectors is very common, but coordination difficulties, there are often prevarication, procrastination phenomenon. Sometimes a small problem will require the company leadership to be resolved, thus seriously affecting the efficiency and production schedules; from a vertical perspective, resulting in a higher level of production of small technical problems after, you want to have to report back by layer level reporting, and finally to chief engineer that might have gone through six or seven, also in the promotion of new technologies and new requirements issued, also need to be passed down the layers, resulting in a low efficiency of information communication, even in the face of production problems not solved in time [3].

\section{B. Extensive Production Planning and Low Production Efficiency}

Aviation manufacturing enterprises produce a variety of products with various components. Meanwhile, because of the difference in the production cycle and product process of various parts, the difficulty in making the production plan is difficult, and the phenomenon of extensive production planning is widespread. The production plan sometimes has no practical guidance value. Sometimes, due to various factors, the abortion of the plan, which leads to the lack of rigid and executive power, seriously affected the actual production efficiency, the production plan and the actual production of the phenomenon also occurs, resulting in a disorderly production state.

\section{Lack of Standards and Numerous Quality Problems}

China's aviation industry has been integrated for many years, but the different standards of enterprises and Research Institute are still in use, which leads to the standard of non uniform, and therefore, the standard of inspection is not uniform, resulting in the emergence of quality problems. In the enterprise, although the product process standards can achieve effective implementation, but some other standards in the implementation of the very difficult, such as some small quantities of parts standard, they are just the concept of meaning, the implementation is very difficult; some standards and production process does not conform to the implementation; some although consistent with the production process, but there is no corresponding quantitative assessment indicators, still can not be accurately measured and implemented. In short, because of the lack of uniform and scientific standards, the quality of many parts, which lead to a lot of rework and scrap, reducing the production efficiency and increasing the production cost [4].

\section{IMPROVEMENT OF LEAN PRODUCTION IN CHINA'S}

\section{AVIATION MANUFACTURERS}

Lean production is the most advanced production management concept, but also a kind of corporate culture, it advocates the elimination of waste, better to create value. Once the implementation of lean production enterprises, enterprises and individuals to pursue the goal of unity, for the continuous improvement of enterprise production 
process to provide a strong spiritual power, but also to maximize the value of personal and business efficiency, in the process of continuous pursuit of zero waste of continuous development and improvement, so that enterprises become more powerful. The use of lean production to obtain good results of the aviation manufacturing enterprises examples abound, such as the United States of Boeing, The Aerospace Corporation, etc., they are without exception the use of lean production. In order to make constantly development and progress as well as shorten the gap with advanced foreign level, China' $s$ aviation industry must implement lean production.

In terms of the actual condition of China's aviation manufacturing enterprises, in order to implement lean production for improvement, they should begin with the several following aspects:

First, Streamlining personnel structure. We have also mentioned previously that most aviation manufacturing enterprises use the functional organization forms with various and overstaffing organizational level, greatly hindering communication and exchange between each depart. Therefore, organization structure must be optimized to reduce organizational level and the amount of non-direct production personnel and try as much as possible to maintain smooth communication and convenient information exchange between staffs.

Second, Strengthen communication and coordination between departments, synchronize production planning and sales and improve enterprises' strain capacity in production. Rationalize production process, greatly reduce inventory to even zero inventory. Also, reduce waste of each link, effectively improve production efficiency and reduce costs.

Third, Establish management standards. In terms of organization and process, improve and optimize standards that do not match to form a strict and scientific production management standard system. Meanwhile, establish quality supervision system, greatly improve product quality and remove potential quality problems in production to constantly pursue the goal of zero defect to products [4,5].

\section{EFFECTIVE MEASURES TO GUARANTEE AND IMPROVE}

\section{LEAN PRODUCTION}

\section{A. Information Management of Production Factors}

In order to implement lean production, the first thing to do is information management. Only when we have timely and accurately mastered production information can a scientific and effective production scheme be further promulgated, so the three following aspects should be taken into account:

First, well manage basic data of each product element so as to comprehensively and systematically get to know the status of each main body in production.

Second, collate and perfect production techniques and bills of materials. Meanwhile, make corresponding dynamic management according to different statuses of each main body.

Three, Collect and process various information during production, which is also to lay a technical foundation for management.

\section{A. Train Staffs to Adapt to Lean Production and Management}

Staffs are the main body of an enterprise, so their enthusiasm is the vital factor associated with the level of production efficiency. Therefore, staffs of an enterprise must be trained in lean production and training schemes at different levels should be developed targeted at different systems. In order to improve staffs' enthusiasm in learning, appropriate incentive mechanism should be developed to guarantee staffs' enthusiasm and adaptability. Meanwhile, emphasis should also be put on the strength of the frontline staffs to encourage all the staffs to constantly innovate, improve and optimize the production procedure during the production process. In addition, full play should also be given to staffs' initiative to enhance the enterprise's cohesion and sense of responsibility and create a situation of constantly improving production through the joint effort of all the staffs [5].

\section{B. Establish Corporate Culture of Lean Production}

"Interpersonal relationship" plays an important role in Chinese culture with profound impact, so it also exists in enterprises. Due to the existence of "interpersonal relationship", some leaders and cadres cannot timely rectify the mistakes made by their staffs, thus it is hardly to implement lean production. Meanwhile, when similar problems occur, some leaders just purely give punishment, which cannot achieve the desired effect either. And instead, it will trigger resentment of staffs. Therefore, corporate culture of lean production should be established to help enterprises guide and motivate employees to pay attention to team cooperation and work efficiency. "Interpersonal relationship" should not appear in such corporate management, and managers should focus on production and staffs to actively take effective measures and listen to employees' opinions and suggestions so as to make the majority of employees get involved in improving production and management and feel that each of them is an important part of the enterprise, thus they will have the sense of responsibility and enthusiasm.

\section{Establish Management over Lean Production Planning}

In order to implement lean production, more emphasis should be put on managing production plans, and refined production plans should be developed through module data base management model. Such plan is more reasonable and scientific and more feasible in implementation. Also, such management can make the management of production plans more refined and accurate with more regulated control. Plans at each level are independent and could also be completed together, thus finally well implementing plans and developing good project plans. Also, timely feedback can be received [6].

\section{Overall Improvement of Lean Production}

Lean production cannot only improve the production link, and some non-production departments like procurement, sales and finance can also be improved by using lean production theory. Each link like capital, supply, warehouse and transportation can be optimized and managed with this theory so as to truly make reach department and link become lean in the entire aviation 
manufacturing industry, which will greatly optimize the management environment of lean production.

In terms of characteristics of the aviation manufacturing industry itself, it is closely associated with the security of national defense and economic development, so there is no need to mention its importance. However, as far as the current situation is concerned, China still lags far behind foreign developed countries in the aviation manufacturing industry, and lean production begins to be implemented in a lot of manufacturing industries in China with excellent results. As a discrete manufacturing industry, the efficiency of the traditional aviation manufacturing management mode is low, and can effectively improve the original low management mode, optimize the structure of the organization to make the communication more smoothly, and can reduce the waste of resources and product defect rate, improve product quality. However, to implement the lean production also needs the support and cooperation of the information management technology, and the establishment of the enterprise culture. All in all, the effective implementation of lean production can make enterprise's various departments, various links to improve and improve, improve enterprise productivity, improve product quality, but also enhance the competitiveness of enterprises.

\section{ACKNOWLEDGMENT}

The work is supported by the Aviation Foundation (2013ZG54034).

\section{REFERENCES}

[1] Qi Changgui, Liu zhenzhong, Wang Huaiyu. Research into Internal Supply Chain Management of Aviation Manufacturers [J]. Aviation Manufacturing Technology. 2012(06)

[2] Luo Chang, Zhang Cheng, Jia Suling, Wang Huiwen. New Mode of Technical Reform and Project Management in Large Aviation Manufacturers [J]. Journal of Beihang University (Social Science Edition). 2007(04)

[3] Chen Yongman, Feng Ziming, Deng Yudong. Technology Management System and Technological Innovation with Multiple Projects in Aviation Manufacturers [J]. Aviation Science and Technology. 2003(03)

[4] Cheng He. From Lean Manufacturing to Lean Enterprises [J]. New Technology and New Process. 2013(10).

[5] Wang Shen. Application of Lean Manufacturing and Manufacturing and Implementation System in Aviation Manufacturing Enterprises [J]. Aviation Manufacturing Technology, 2008,19:42-45.

[6] Yang Qingqing. Improvement of Aviation Manufacturing Enterprises' Independent Innovation Ability and Choice of Route [J]. Modern Enterprises. 2013(12). 